\title{
Peertechz
}

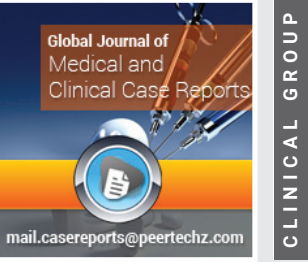

\section{What we Learned from}

\section{Covid19 on behalf of Hospital} Management?

\author{
Malhan $\mathbf{S}^{1 *}$, Torgay $A^{2}$, Kavuncubası $\mathbf{S}^{1}$, Alzhanov $\mathbf{S}^{3}$, \\ Kikimbayeva $\mathrm{R}^{4}$, Malchenko $\mathrm{V}^{5}$, Zhunussov $\mathrm{Y}^{6}$ and Haberal $\mathrm{A}^{7}$ \\ 'Department of Healthcare Management, Baskent University, Turkey \\ ${ }^{2}$ Medical Director, Baskent University Ankara Hospital, Turkey \\ ${ }^{3}$ Medical Director, Semey Medical University Hospital, Kazakhstan \\ ${ }^{4}$ Deputy Director for Medical Work, Semey Medical University Hospital, Kazakhstan \\ ${ }^{5}$ Manager Physician, Semey Medical University Hospital, Kazakhstan \\ ${ }^{6}$ Chairman of the Board-Rector, Semey Medical University, Kazakhstan \\ ${ }^{7}$ HealthGroup Director, Rector, Baskent University, Turkey
}

Received: 21 October, 2020

Accepted: 06 November, 2020

Published: 07 November, 2020

*Corresponding author: Simten Malhan, PhD, Professor, Department of Health Care Management, Baskent University, Ankara, Turkey, Tel: +903122664646; E-mail: bmalhan@baskent.edu.tr; simtenmalhan1@gmail.com

Keywords: COVID19; Hospital management; Cost of disease

https://www.peertechz.com

\section{Check for updates}

\section{Abstract \\ Aim: Our aim is to take an attention to hospital management concept during COVID19. \\ Method: We searched pubmed with key words ; hospital, management, and COVID and reached 2054 articles. 1881 articles were full texts. We searched all abstracts and determined 357 systematic review and meta-analysis. But only 40 articles were directly related to hospital management and COVID-19. 40 articles were interpreted and areas for hospital managers to study were determined.}

Result: The articles about hospital management are not enough to reference to other countries. So countries should publish their experiences and also we have to learn cost of COVID in order to find good practices for hospital management

Conclusion: Literature needs more articles about hospital management concept.

Coronavirus disease 2019 (COVID-19) is a declared global pandemic. Although scientists stimulated the world against the new pandemic, neither developed nor developing countries are prepared. The 2019 novel coronavirus (2019-nCoV), born in a wet market in Wuhan, Hubei province, China at the end of 2019, has gained intense attention nationwide and globally [1]. As known, hospital management is a very complex issue. After COVID-19, it became more complex than before. We watch developed countries' health systems and understand how much more hospital management is important. In order to provide sustainability and access to health services, hospital managers in a micro level and health system administrators in a macro level need pro-active strategies. COVID-19 taught us we need to deal with communicable diseases as much as non-communicable diseases. Because we still haven't won the fight against communicable diseases. That's why we searched hospital management concept through the countries' examples. Until June $20^{\text {th }}, 2020,23,350$ articles have been published about COVID-19 in Pubmed. We use hospital, management and COVID as key words and reached 2054 articles. 1881 articles were full texts. We searched all abstracts and determined 357 systematic review and meta-analysis. But only 40 articles were directly related to hospital management and COVID-19. 40 articles were interpreted and areas for hospital managers to study were determined. In our opinion, the number of publications related to hospital management is quite small. The global health system needs to spend more energy on this issue to meet people's unlimited demands and needs. Hospitals should work to achieve maximum health output at low cost. Although health managers agree to manage 
resources at low costs, unfortunately, it is not quite possible in the conditions we are in. Even in developed countries around the world, we are witnessing that resources are running out and patients are unable to access services. Because hospitals faced long hospitalizations, intensive care, unexpected drug use, caused by the course of the disease. Since we learned about the disease recently, there were many changes in the clinical treatment processes, and many health services had to be passive until the treatment algorithm was established. In addition, many unwanted terminations, long hospitalizations, the use of resources above the optimum amount in the face of an unexpected pandemic have rendered many countries' health systems unsustainable.

If hospital managements can effectively distribute its resources by taking proactive strategies, it will ensure their sustainability, but other than that, it is the insurances and health policies adopted by states that will ensure the financial sustainability of hospital managements. What was the cost of COVID-19 patients in particular? What will happen? Given the changes in treatment protocols and unforeseen case increases and pessimistic scenarios, how far the costs will rise? We need more information on both optimistic and pessimistic scenarios. For this reason, on the articles we examined, we determined that they focus on management and demand forecast of intensive care, capacity, hospitalizations, medicines, operation rooms and emergency departments [214]. We also noticed epidemiological studies and studies related to public health management captures managements' interest. We think the next stage is to calculate the cost of the disease as soon as possible. As we seen, due to lack of intensive care bed, the hospitals worked over capacity and also transferred their patients to the other hospitals. At the same time because of unexpected pandemic, interior hospital was reorganized. Such as several medical and surgical units were dismantled, to create dedicated COVID-19 units, rapidly occupied by patients undergoing respiratory support. Non-Covid19 patients was discharged or transferred external hospital before completed treatment [15]. It means that cost is going up. Bartsch, et al. developed a direct medical cost model for US citizens who got infected. It is an estimation model in order to understand the potential economic benefits of reducing the burden of the disease. A single symptomatic COVID-19 case could incur a median direct medical cost of $\$ 3,045$ during the course of the infection alone. If 80 percent of the US population were to get infected, the result could be a median of 44.6 million hospitalizations, 10.7 million intensive care unit (ICU) admissions, 6.5 million patients requiring a ventilator, 249.5 million hospital bed days, and $\$ 654.0$ billion in direct medical costs over the course of the pandemic. If 20 percent of the US population were to get infected, there could be a median of 11.2 million hospitalizations, 2.7 million ICU admissions, 1.6 million patients requiring a ventilator, 62.3 million hospital bed days, and $\$ 163.4$ billion in direct medical costs over the course of the pandemic [16]. These results show that if health authorities do not manage infection, the limited resources will not against requirement of sick people. Also the health system's viability is in danger. That's why countries need to benchmark of different health care management. Only after then, pro-active strategies can be carried out.

\section{References}

1. Xiang YT, Yang Y, Li W, Zhang L, Zhang Q, et al. (2020) Timely mental health care for the 2019 novel coronavirus outbreak is urgently needed. Lancet Psychiatry 7: 228-229. Link: https://bit.ly/36dlyB|

2. Kakodkar P, Kaka N, Baig MN (2020) A Comprehensive Literature Review on the Clinical Presentation, and Management of the Pandemic Coronavirus Disease 2019 (COVID-19). Cureus 12: e7560. Link: https://bit.ly/38ilW39

3. Li R, Rivers C, Ran Q, Murray MB, Toner E, et al. (2020) Estimated Demand for US Hospital Inpatient and Intensive Care Unit Beds for Patients With COVID-19 Based on Comparisons With Wuhan and Guangzhou, China. JAMA Netw Open 3: e208297. Link: https://bit.ly/38nxOBY

4. Cao Y, Li Q, Chen J, Guo X, Miao C, et al. (2020) Hospital Emergency Management Plan During the COVID-19 Epidemic. Acad Emerg Med 27: 309311. Link: https://bit.ly/2ld45AQ

5. Phua J, Weng L, Ling L, Egi M, Lim CM, et al. (2020) Intensive Care Management of Coronavirus Disease 2019 (COVID-19): Challenges and Recommendations. Lancet Respir Med 8: 506-517. Link: https://bit.ly/3p2Ycad

6. Wong J, Goh QY, Tan Z, Lie SA, Tay YC, et al. (2020) Preparing for a COVID-19 Pandemic: A Review of Operating Room Outbreak Response Measures in a Large Tertiary Hospital in Singapore. J Anaesth 67: 732-745. Link: https://bit.ly/2UfFXAp

7. Garg M, Wray CM (2020) Hospital Medicine Management in the Time of COVID-19: Preparing for a Sprint and a Marathon. J Hosp Med 15: 305-307. Link: https://bit.ly/3p7afmQ

8. Tsai TC, Jacobson BH, Jha AK (2020) American Hospital Capacity And Projected Need for COVID-19 Patient Care. Health Affairs. Link: https://bit.ly/3k5R1KE

9. Chopra V, Toner E, Waldhorn R, Washer L (2020) How Should U.S. Hospitals Prepare for Coronavirus Disease 2019 (COVID-19)? Ann Intern Med 172: 621 622. Link: https://bit.ly/32lpUFj

10. Meier KA, Jerardi KE, Statile AM, Shah SS (2020) Pediatric Hospital Medicine Management, Staffing, and Well-being in the Face of COVID-19. J Hosp Med 15: 308-310. Link: https://bit.ly/3n01s4j

11. Remuzzi A, Remuzzi G (2020) COVID-19 and Italy: What Next? Lancet 395 1225-1228. Link: https://bit.ly/32j8Q32

12. Carenzo L, Costantini E, Greco M, Barra FL, Rendiniello V, et al. (2020) Hospital Surge Capacity in a Tertiary Emergency Referral Centre During the COVID-19 Outbreak in Italy. Anaesthesia 75: 928-934. Link: https://bit.ly/2U07aqj

13. Leibner ES, Stokes S, Ahmad D, Legome E (2020) Emergency Department COVID Management Policies: One Institution's Experience and Lessons Learned. Emerg Med Pract 22: 1. Link: https://bit.ly/35aRHKN

14. (2020) Swiss Society Of Intensive Care Recommendations for the Admission of Patients With COVID-19 to Intensive Care and Intermediate Care Units (ICUs and IMCUs) MedicineSwiss Med Weekly. 150:w20227.

15. Buoro S, Di Marco F, Rizzi M, Fabretti F, Luca Lorini F, et al. (2020) Papa Giovanni XXIII Bergamo Hospital at the time of the COVID-19 outbreak: Letter from the warfront. Int J Lab Hematol. Link: https://bit.ly/38ISISe

16. Bartsch MS, Ferguson MC, McKinnell AJ, Kelly OJ, Wedlock TP, et al. (2020) Associated With COVID-19 In The United States. Health Aff 39: 927-935.

Citation: Malhan S, Torgay A, Kavuncubası S, Alzhanov S, Kikimbayeva R, et al. (2020) What we Learned from Covid19 on behalf of Hospital Management? Glob $J$ Medical Clin Case Rep 7(2): 107-108. DOI: https://dx.doi.org/10.17352/2455-5282.000110 